\title{
Stress Issues at Pajingo Mine
}

\author{
R.K. Whiting Newmont Pajingo Limited, Australia
}

\begin{abstract}
Newmont Asia Pacific operates the Pajingo gold mine exploiting a series of narrow mineralised quartz veins commonly referred to as the Vera-Nancy system. An underground operation since 1995, the site has recently encountered stress related problems at mining depths of greater than $450 \mathrm{~m}$ below surface. Deterioration of conditions at depth include intact rock failure, stress induced wedge failures, minor seismicity and significant damage to reinforcement and hole closures with drilled stocks in advance of the mining front.

Specifically, the mine has shown stress conditions and rock mass damage that are difficult to control when using a benching method which retreats to centrally located crosscuts below $450 \mathrm{~m}$.

The design for the Jandam mining area was changed from a central retreat extraction method (using a single crosscut access) to a more development intensive end access, centre out mining sequence, designed to minimise stress induced damage. This allowed adoption of a key design modification in the form of an inclined mining front with simultaneous production from multiple mining levels.

Successive extraction of individual panels with prescribed lead-lag distances allowed shedding of stress into stope abutments making mining conditions manageable and maximising predictability and productivity.

This paper will discuss general stress related issues encountered on site and various strategies used to manage the conditions. It will outline the background leading to the choice of mining methods and operational variations adapted to the traditional sub level benching technique to control stress related problems at Pajingo mine.
\end{abstract}

\section{Introduction}

The Pajingo Gold mine owned and operated by Newmont Asia Pacific is located on three mining leases, approximately 53 kms SSE of Charters Towers in Queensland, Australia (Figure 1). Epithermal style gold mineralisation is hosted by steeply dipping epithermal quartz veins within a thick sequence of andesite flows termed the Mt Janet volcanics (Phillips and Orr, 2007). Underground Mining commenced in 1995 using a sub level benching technique and estimates on current reserves indicate mining will be completed by mid 2008.

Previous mining within the Vera Nancy system encountered stress related problems at depths greater than approximately $450 \mathrm{~m}$ below surface. This included intact rock failure, stress induced wedge failures, minor seismicity and significant damage to reinforcement and hole closures with drilled stocks in advance of the mining front.

Experience with similar ore bodies in the mine has shown that stress conditions and rock mass damage are difficult to control when using a retreat to central crosscut extraction method at this depth range.

Associated effects of the stress conditions contributed to decreased mine safety and excessive dilution significantly impacting the operation profitability. This resulted in a change in mine design for the Jandam mining area from a central retreat extraction method (using a single cross-cut access) to a more development intensive end access/centre out mining sequence designed to minimise stress damage. This allowed adoption of a key design modification i.e. the introduction of an inclined mining front with simultaneous production from multiple mining levels. Successive extraction of individual panels with prescribed lead-lag distances allowed shedding of stress into stope abutments making mining conditions manageable and maximising predictability and productivity. 


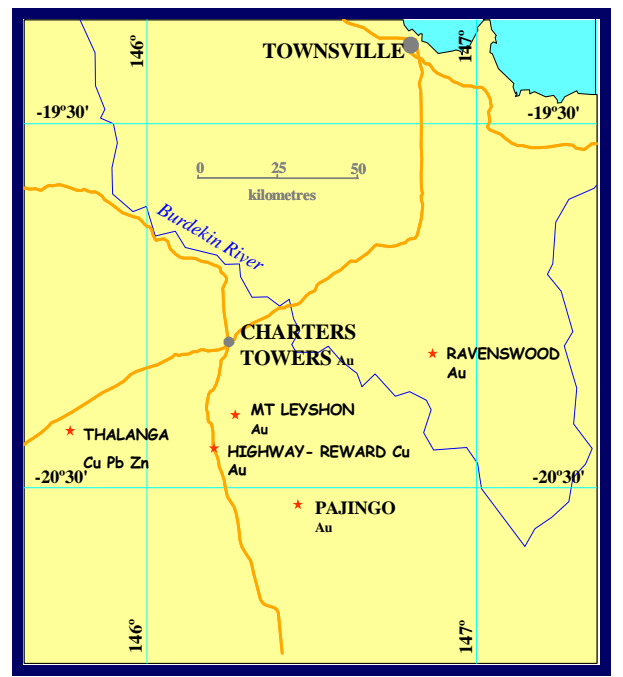

Figure 1 Newmont Pajingo location map

An adjacent mining area in Vera South Deeps requires extraction of remnant crown pillars as other more productive reserves are depleted toward the end of mine life. This project is expected to encounter high stress conditions and challenging mining using a variation of the Sub Level Cave technique. The crown pillar contains approximately $10000 \mathrm{Oz}$ of gold at $530 \mathrm{~m}$ below surface with stopes above and below the crown backfilled with run of mine unconsolidated development waste. The area is characterised by a high strength mineralised quartz vein of over $10 \mathrm{~m}$ width. Strong geological structures and intact rock failure indicate the pre-mining stress state is significant and the rock mass response to mining of the pillar is planned to be documented with the aid of microseismic and other instrumentation.

\section{Geotechnical environment}

\subsection{Structural setting}

The deposits occur in the Northern part of the extensional Drummond Basin. Mineralisation is associated with normal faulting in an area controlled by lystric basin margin faults at various angles to the main extension direction (Phillips and Orr, 2007).

\subsection{Geology}

The andesitic volcanic sequence is the only rock type of significance within the mine and hosts all mineralised quartz veins. It appears as fresh rock in the majority of exposures underground and hydrothermal alteration associated with the veins does not appear to significantly affect its mechanical properties. Typical properties for Mt Janet andesite are shown in Table 1.

Table 1 Typical mechanical properties for Pajingo andesite (Li, 2002)

\begin{tabular}{cc}
\hline UCS (MPa) & $100-150$ \\
Poissons ratio & 0.25 \\
Young’s modulus (GPa) & 46.9 \\
Specific gravity (g/cc) & 2.65 \\
\hline
\end{tabular}

Quartz veins are generally bound within discrete faults and range from vertical to approximately 60 degrees dip. An increase in jointing and faulting is commonly observed in both the hangingwall and footwall of the ore veins and orientated sub-parallel to them thus influencing stope stability and dilution control (Figure 2). 


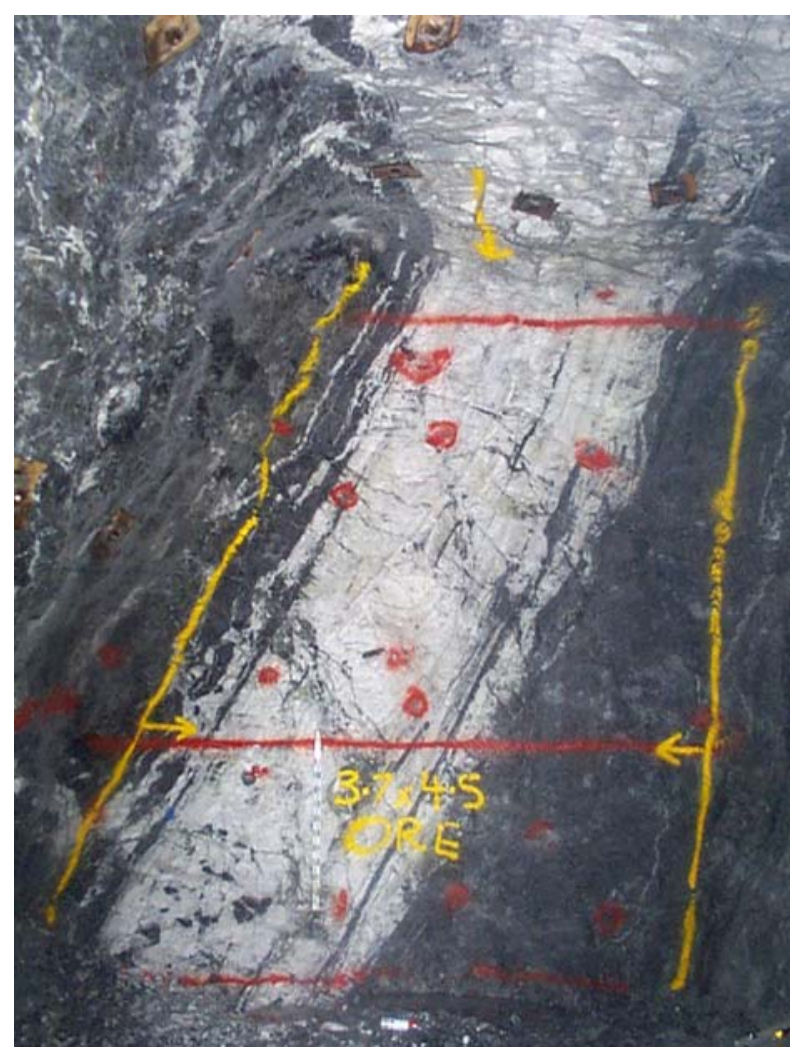

Figure 2 Typical narrow vein

\subsection{Rock mass properties}

In general terms, the rock mass at Pajingo can be described as fair to good quality rock. It is stable under normal conditions, requiring only minor levels of ground support and reinforcement (split sets and mesh). Data produced for the geotechnical block model defines 'geotechnical domains' on the basis of proximity to the main mineralised vein. These values are presented in Table 2 for the Vera South and Jandam orebodies. Due to the strong structural control of faulting on the orebody, good quality, competent zones are of rock are common where geological structures are parallel to ore veins. Where fault structures cross cut the ore structure they are commonly associated with discrete zones of increased jointing and lower quality rock. This causes the rock quality to span a wide range of Q values, and is consistent with the dominant mode of failure in open stopes being driven by the frequency and proximity of strong faults.

Table 2 Q values for each of the 'geotechnical domains' within the Vera, Vera South and Jandam Orebodies ( $\mathrm{P}=$ proximal $0-5 \mathrm{~m})$

\begin{tabular}{ccc}
\hline Domain & Average & Range \\
\hline Vera South & $\mathrm{Q}$ & \\
FW P & 23.6 & $0.006-187.5$ \\
ORE & 22.6 & $0.001-187.5$ \\
HW P & 22 & $0.004-601.8$ \\
Jandam & & \\
FW P & 27 & $0.156-100$ \\
ORE & 33.5 & $0.021-99.8$ \\
HW P & 23.3 & $0.119-99$ \\
\hline
\end{tabular}


Acoustic Emission stress measurements suggest the ratio of stresses is roughly 2:1 horizontal to vertical with maximum principal stress oriented approximately horizontal and perpendicular to the strike of the ore veins. The major, intermediate and minor principal stresses were measured as $33 \mathrm{MPa}, 22 \mathrm{MPa}$ and $15 \mathrm{MPa}$ respectively at a depth of $540 \mathrm{~m}$. The minimum principal stress is directed vertically and matches well with the predicted overburden stresses (Villaescusa, 2002).

\section{Mining methods}

Mining on site has traditionally been based on a bottom up benching technique with retreat to a central crosscut. A modified Avoca sequence is used with run of mine unconsolidated waste rock periodically placed to backfill stopes as the bench is mined from each end toward the centre (Figure 3). The backfill material then forms the floor as the next level is extracted. For the majority of mining undertaken at Pajingo this method has been highly effective with open strike lengths of up to $200 \mathrm{~m}$ (without backfill) achievable in highly competent areas of the orebody.

Development levels are mined at $15 \mathrm{~m}$ vertical intervals (floor to floor). These cross-cuts are then developed as sill drives along the ore at the level interval to the extremity of mineralisation.

The ore between successive levels is mined by drilling and blasting downholes back to the centrally located cross-cuts. Mining of stopes follows a bottom-up sequence with mined out stopes being backfilled with waste from the upper level. The backfilled waste then forms the floor of the next stoping horizon.

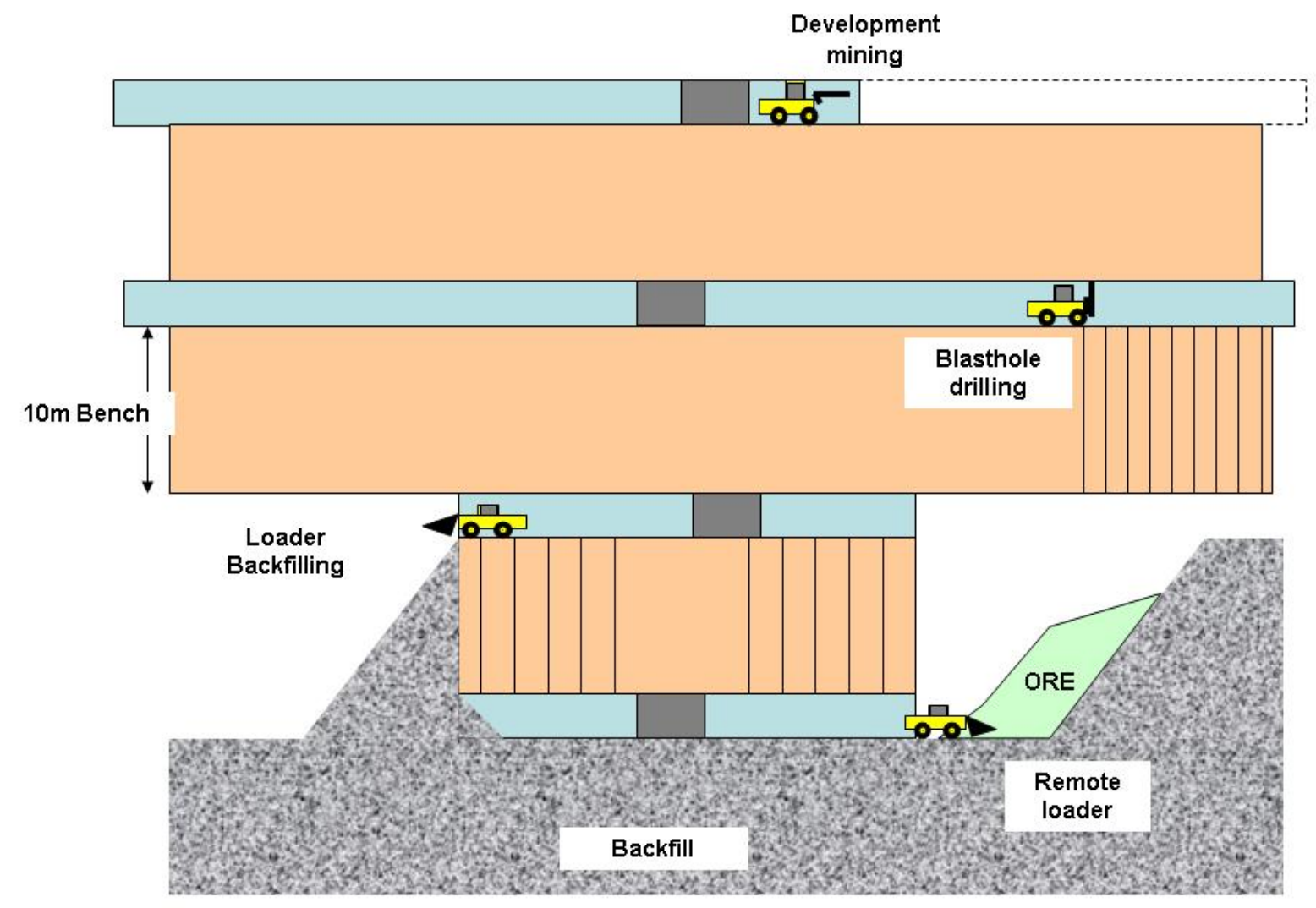

Figure 3 Schematic section of modified Avoca mining method 


\subsection{Typical stope performance}

Conditions in the Vera orebody (maximum 300 m below surface) were so good that stoping was commonly retreated all the way back to the cross-cut on both sides without any backfill (up to $200 \mathrm{~m}$ of stope strike length). The last stope across the intersection was then 'mass' fired. In some cases this caused minor damage to the cross-cut above with cracks forming in the cross-cut pillars. The pillars were scaled but were managed without the need for rehabilitation. There were no reported stress related issues with the mining of these ore bodies at higher elevations within the mine. A typically good performing narrow vein stope within the Vera orebody is show in Figure 4.

The Vera South Upper extraction sequences (400 m maximum depth) adopted the same approach as Vera, with stopes being extended as far as possible on strike before being filled. If they could not reach back to the cross-cut they were periodically filled and rib pillars were left for support, particularly where faults came close to or intersected the orebody.

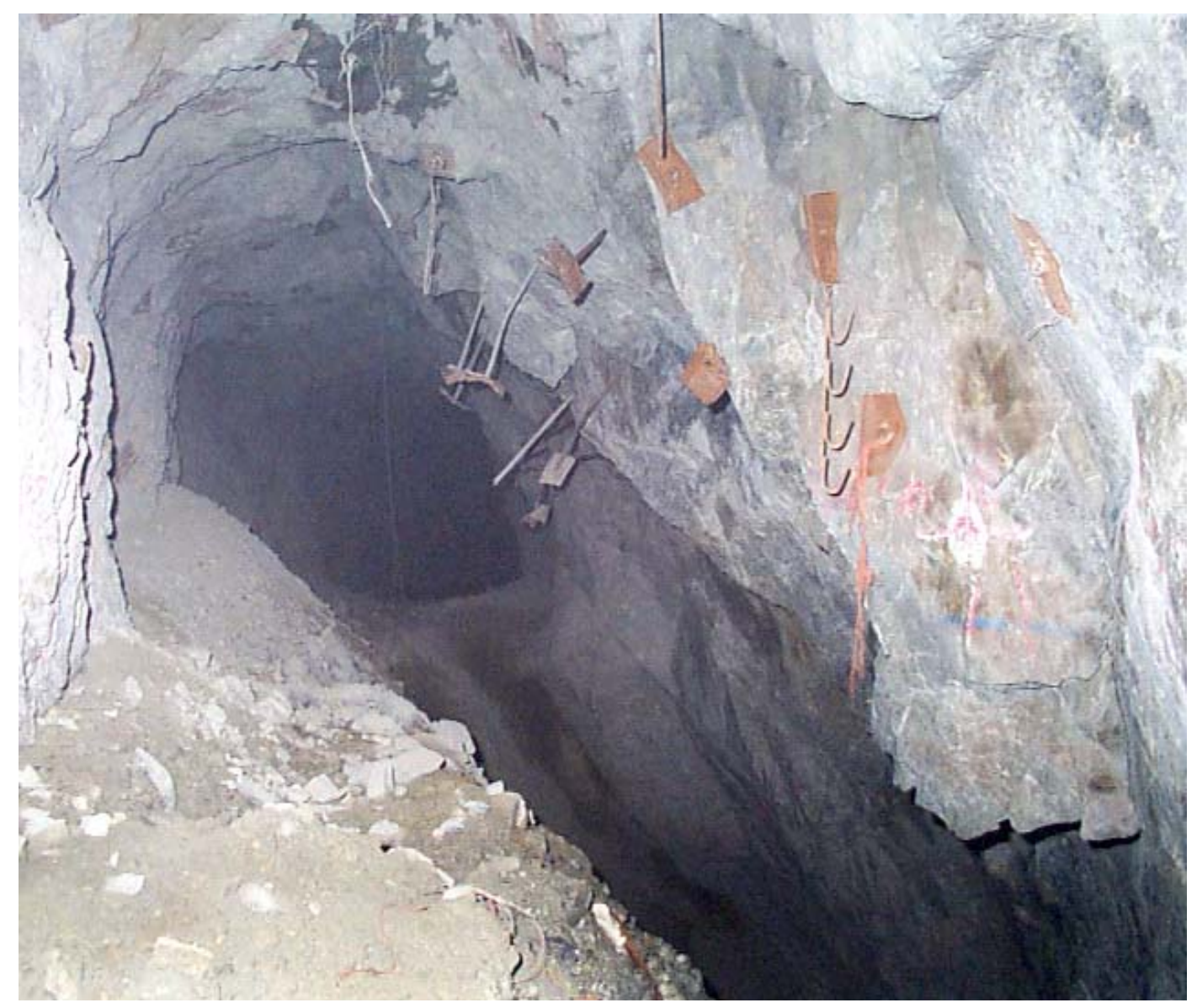

Figure 4 Typical narrow vein stope performance in the Vera orebody

\section{The problem}

\subsection{Jandam}

The Jandam orebody is the deepest of the Pajingo lodes (maximum depth $670 \mathrm{~m}$ ) and is characterised by two sub-parallel vein structures (Figure 4). The veins form a series of steeply dipping ore shoots with a number of linking structures and splays along the main fault trace (Figure 5). Rock mass quality is generally within the 'good' class of rock and the orebody conditions are notably better quality rock than the material comprising the footwall and hangingwall. Initial ground support used during development was split sets and mesh. 


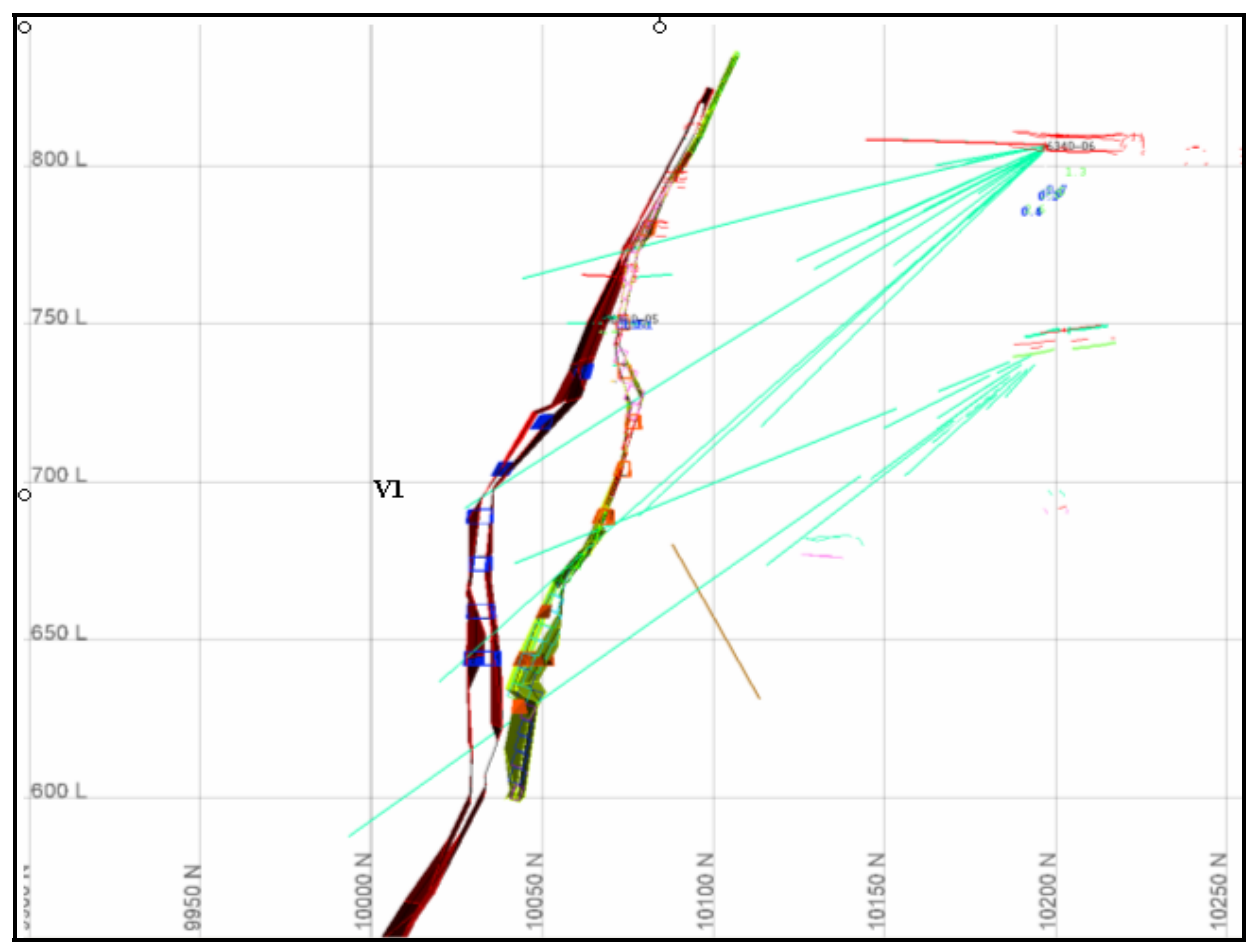

Figure 5 Cross section through sub parallel Jandam lode structures

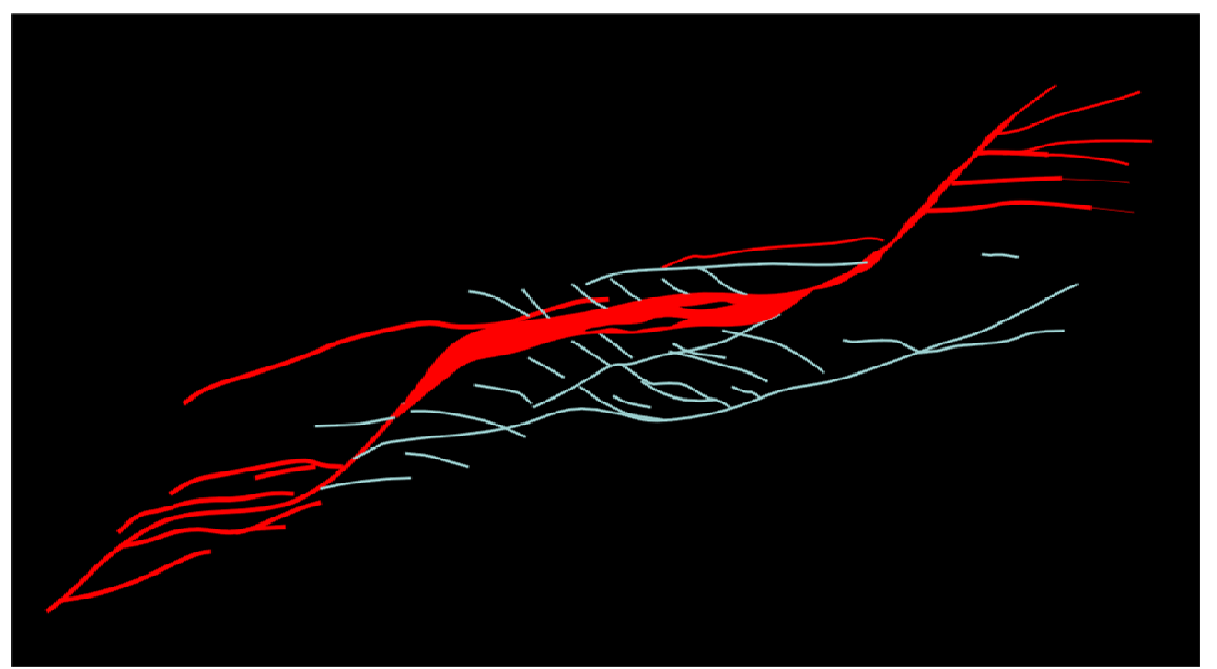

Figure 6 Schematic representation of sinusoidal ore vein (red) and anastomosing complex of splay veins and related faults

\subsubsection{Mining conditions}

The modified Avoca mining method was justified for Jandam based on outstanding previous success in areas such as Vera (as previously mentioned) throughout the mine. Ground conditions appeared similar to elsewhere at Pajingo and initial development mining in the orebody did not present any significant problems.

However the start of production from stopes in October 2004 revealed stope stability problems in the high grade J2 structure with orebody parallel/sub-parallel faults presenting a challenge to maintaining stable stope walls. As mining progressed structurally controlled stope wall failures continued to impact heavily on the Jandam production increasing unplanned dilution in the J2 vein from 5 to 25\% for the December 2004 reserves estimation. Stable open strike lengths decreased to approximately 10-15 m, with stope brows often damaged and drilled holes unusable. 
As extraction of the orebody increased, the modified Avoca sequence which had worked so well for Pajingo for many years started to show more signs of stress induced damage. Ground conditions in advance of the mining front started to deteriorate and a number of mining steps which were standard procedure started to become unachievable making mining conditions difficult such as (Figure 7 and 8):

- Spontaneous falls of ground.

- Hole closure causing redrills, no drilled stocks.

- Extensive rehabilitation in advance of stoping front required.

- Ground movement/ displacements not controllable with standard ground support.

- Slow mining with major interruptions to mining schedule.

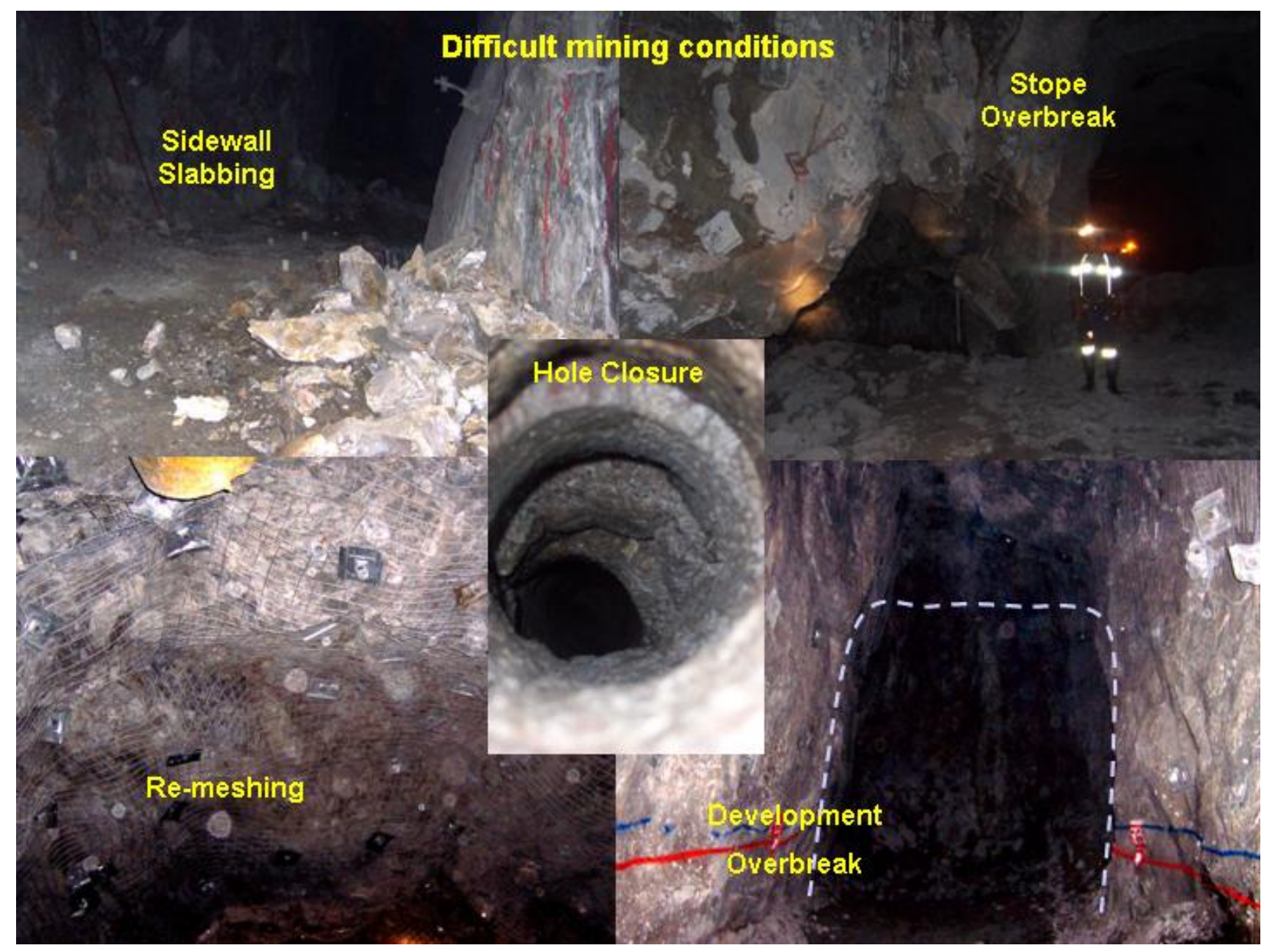

Figure 7 Examples of stress induced damage in the Jandam orebody 


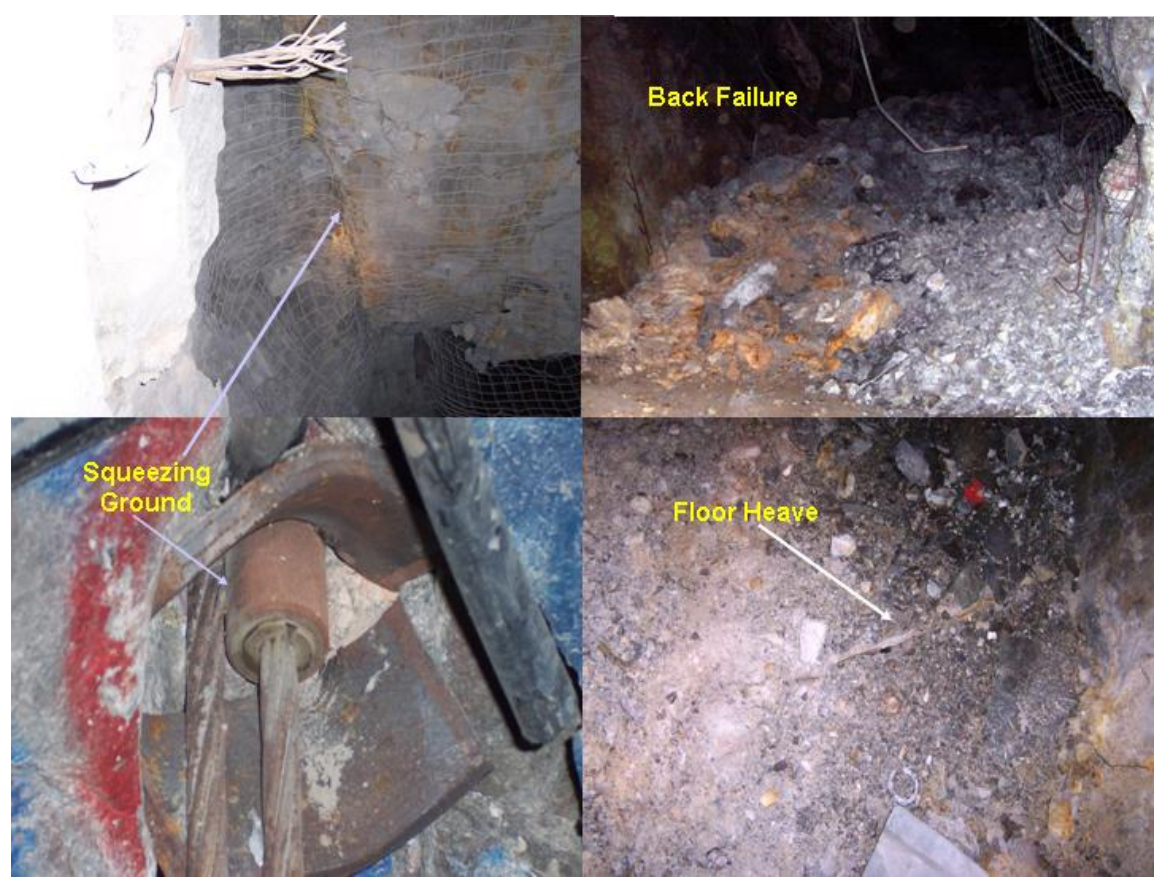

Figure 8 Damage to ground support and poor mining conditions in Jandam mining area

\subsubsection{Modelling results}

Numerical stress modelling completed after the onset of the difficult mining conditions in Jandam indicated that mining induced stress conditions were the likely driving force behind the deterioration. The high stress conditions were exacerbated by the central retreat mining sequence which concentrated stresses within a shrinking pillar centred on the cross-cut area. Continuation of the standard central retreat extraction was likely to incur major ore loss by creating unmanageable conditions in critical areas such as cross cuts which placed at risk the recovery of substantial volumes of the mining resource (Figure 9).

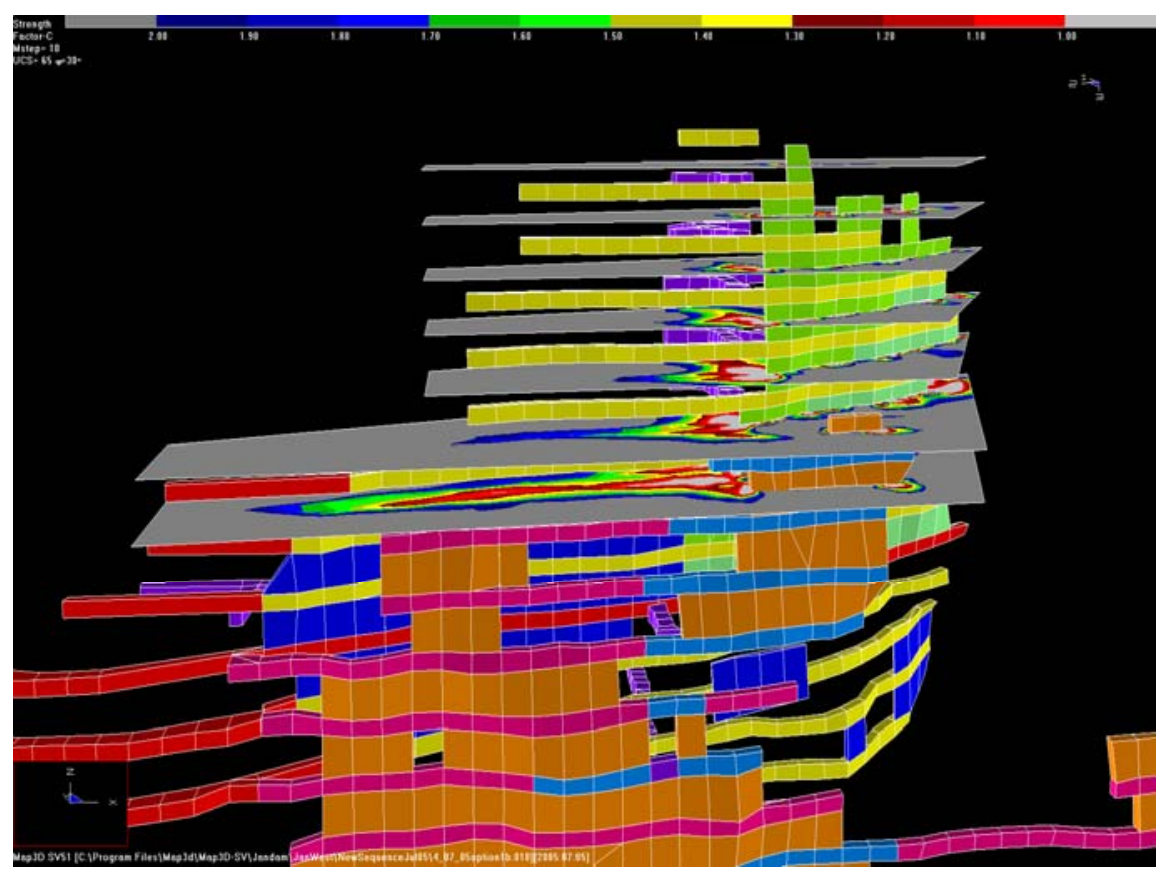

Figure 9 Map 3D model showing safety factor plot of the proposed Jandam extraction sequence (after Ascott, 2005) 


\subsubsection{Design Improvements to manage stress}

The need to manage mining induced stresses forced the development of an alternative method which proposed to construct end accesses to the orebody and extract using a modified Avoca method using inclined front (Figure 10). The inclined mining front operates on multiple levels with a 20-30 m lead-lag distance and sheds stress to the stope abutments rather than concentrating stress on a shrinking central pillar. This allowed mining to continue from the centre of the orebody out toward the extremities. A true Avoca mining and backfill operation was achieved while access was available from the central cross cuts which then reverted to a modified Avoca after backfilling had passed the central access. Upgraded ground support prescribed to control the stress damage and dislocation along structures included debonded cable bolts throughout the length of ore drives and fully grouted split set bolts.

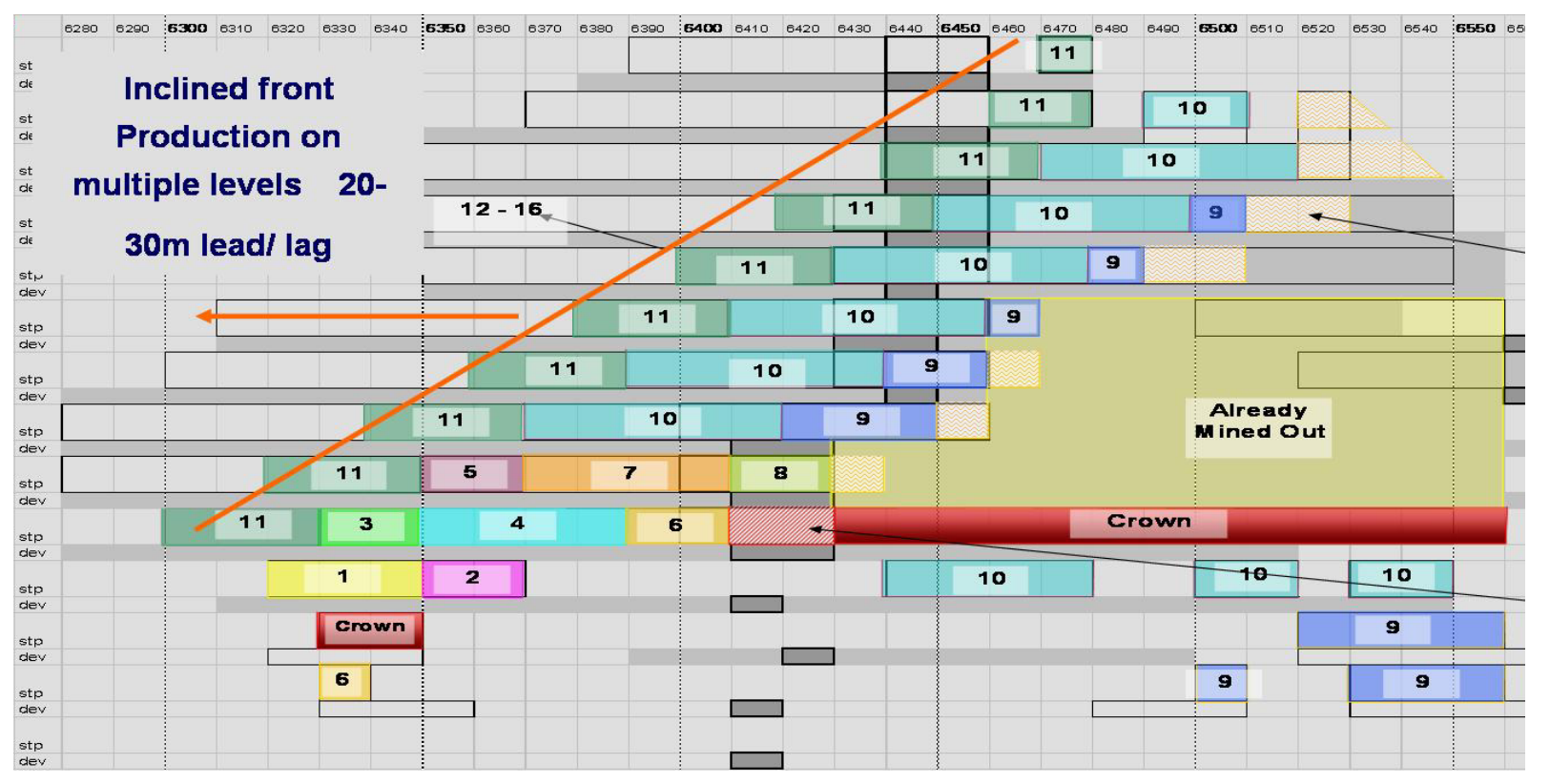

Figure 10 Schematic long section of Jandam inclined mining front and end access extraction. Numbered blocks represent order of extraction (after Ascott, 2005)

The design modifications had the added bonus of dramatically improving the extraction ratio (>16000 Oz) as well as accelerating access to high grade ore through the introduction of multiple production levels. Damage at stope brows is still evident but restricted to within the lead-lag distance of stopes. It is now at a much more manageable level as are pre-drilled production hole closures and deformation/dislocation magnitudes.

The improved mining conditions have led to a measurable safety improvement and the need for rehabilitation of development drives is greatly reduced.

The control of stress induced deformation appears to have had a positive influence on minimising stope dilution and have significantly improved predictability and continuity of production from a previously problematic area.

\subsubsection{Tactical improvements to control dilution}

Improved dilution control within stopes was a direct result of the design changes to incorporate the end extraction sequence. It is suspected that part of this improvement may be a function of the improved stress conditions which areas are subjected to with the revised extraction sequence.

Other tactical modifications used in conjunction with the changed mining sequence have contributed to the dilution decrease. These include the use of low-strength explosives where faulting exists within $\sim 1 \mathrm{~m}$ of the ore vein contacts. This can result in reduced damage to stope walls and preservation of the waste material intact on the stope walls. Selective cable bolting of stope walls is also implemented where major structures are identified. 
The geometry of the ore drives has been identified as a major factor in many stope failures. Naturally unstable 'bull noses' created on the inside curve of a bend in the ore drive commonly slide into open stopes when they are undercut by the level below. Recognising that the presence of sub-horizontal release planes are related to these bends open stope lengths are generally limited to half the length of an inside curve on a bend and not more than $20 \mathrm{~m}$ when on a straight. This utilises the backfill as the restraining mechanism for the failures.

\subsection{Vera South Deeps}

Vera South Deeps mine has extracted the majority of the V1 vein structure along strike to the East of the Jandam orebody. It extends to a maximum depth of $570 \mathrm{~m}$ below surface with the bulk of the mineralisation within veins of up to $18 \mathrm{~m}$ width between 520-400 m depth (Figure 11). Ground conditions are within 'good' quality class of rock and standard primary ground support is split sets and mesh.

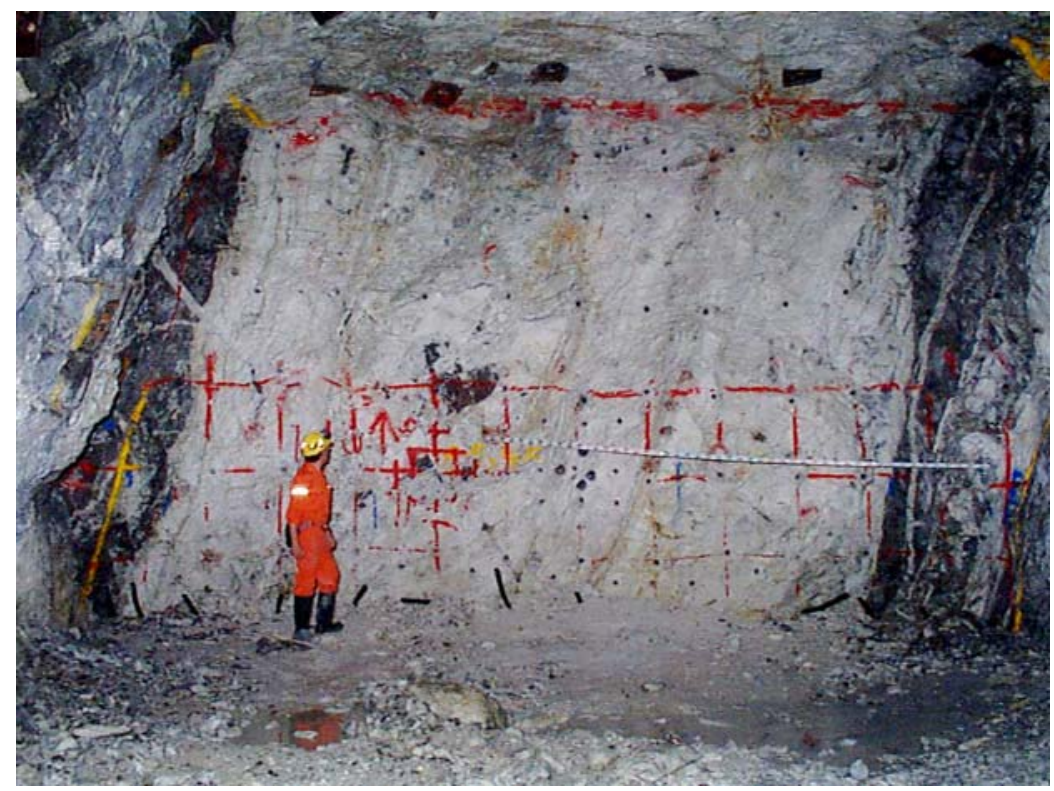

\section{Figure 11 Typical wide quartz vein}

\subsubsection{Mining conditions}

Structural controls on the Vera South Deeps ore vein are dominated by the Crown fault zone, which consists in a series of strong, planar, steeply dipping structures bounding the vein package and occasionally intersecting veins. Ore veins of up to $18 \mathrm{~m}$ width and $200 \mathrm{~m}$ in strike length bearing gold grades commonly measured in 10's to 100's of grams were planned to be mined with a central retreat sequence using a 'modified Avoca' method.

The mining design was based on previous Pajingo standards and placed development levels at $15 \mathrm{~m}$ vertical intervals. A combination of poor orebody understanding and poor mining practice caused the wide veins to be developed out to their full width (maximum $20 \mathrm{~m}$ ) thus creating unstable pillar geometries between sub levels in some cases up to $18 \mathrm{~m}$ horizontal x $8 \mathrm{~m}$ vertical.

Challenges also existed where cross-cut drives intersected the ore veins at locations where a number of conditions coincide to create unfavourable mining conditions. These include (see Figure 12):

- Widest point of ore vein - This existed because of fault offset and duplication of the ore structure.

- Heavily structured area - cross cutting faults common in crosscut area.

- Highest grade.

- Highest mining induced stress conditions due to central retreat extraction. 


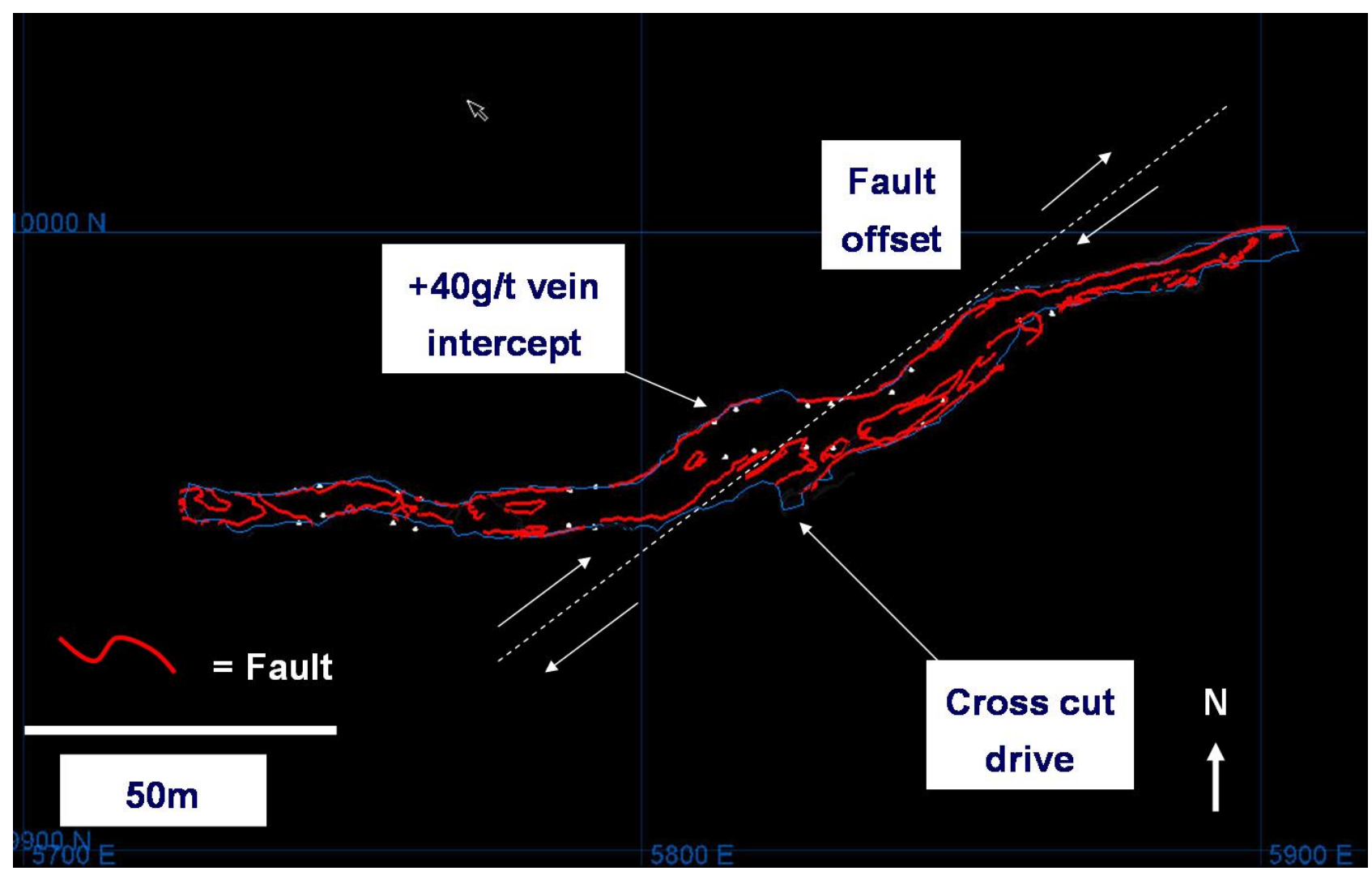

Figure 12 Plan view of Vera South Deeps 840 level fault mapping. This shows $\mathrm{x} /$ cut intersection coinciding with the highest grade, most structure and widest span of the ore drive which would be subjected to the highest stress loading

\subsubsection{Improvements}

These design and geological conditions combined to develop mild seismicity generated by movement along geological structures. Reporting of ground noise events from underground increased in frequency and intensity. Subsequent installation of a microseismic system showed common events in the range of -3 to -1 magnitude.

A large uncontrolled fall of ground in the widest of the ore drives initiated a design review of the Vera South Deeps area just as the first of the stope blocks came into production (Marisett, 2004).

The design review highlighted the extreme width: height ratio of sill pillars $(\sim 0.5)$ which might normally be considered as transitionally stable or unstable under moderate confining stress conditions.

These observations outlined the unsustainability of the central retreat mining method and recommended construction of end access drives to allow extraction from the centre out toward the extremities.

\subsubsection{Current projects}

Extraction of a crown pillar of $10 \mathrm{~m}$ high x $12 \mathrm{~m}$ wide within the Vera South Deeps orebody is planned for $4^{\text {th }}$ Quarter 2007. This remnant mining at approximately $530 \mathrm{~m}$ depth involves a variation of the Sub Level Cave technique where unconsolidated fill above the crown is induced to cave as the pillar is mined in a retreat sequence from the centre out toward end access drives. High stress conditions are expected and potentially difficult brow control problems have been indicated in numerical modelling of the extraction sequence. Instrumentation to monitor the crown pillar performance and response to mining includes SMART $^{\circledR}$ cables, extensometers and a microseismic system.

The mining method used for this pillar has been evaluated after discounting a series of other options on the basis of safety, productivity and practicality. Other options considered were: 
a) Grout consolidation of the loose fill above the crown - this method was discounted following testing which showed specialised grout was not able to achieve sufficient penetration through the fill material, and required mix water with low dissolved mineral contents making reticulated mine water unsuitable.

b) Uphole extraction leaving a thin intact skin pillar - This method was discounted due to the inability to guarantee the integrity of a thin pillar thus creating a potential fill inrush hazard.

\section{Conclusions}

Pajingo mine has applied various methods to manage stress induced mining problems within a narrow vein mining environment. Consideration of ore drive geometry, dominant geological structures and stope strike length are indicators used regularly to guide production scheduling and expected stope performance and minimise dilution. Modified extraction sequences and the use of an inclined mining front have improved mining conditions and brought predictable production from the mine while also allowing early access to superior gold grades. Improved safety and reduced rehabilitation within the mine have been major benefits of the design and sequencing modifications.

\section{Acknowledgements}

The author would like to thank the management of Newmont Pajingo for permission to publish this paper as well as Michael Dunn, Brett Ascott and Scott Marisett for their assistance.

\section{References}

Ascott, B. (2005) Support requirements for Jandam Extraction Sequences. Newmont Pajingo Internal Memo.

Li, J. (2002) Report on Rock Property Testing for Pajingo. West Australian School of Mines, Curtin University.

Marisett, S. (2004) Draft Modelling review of Vera South Deeps Extraction. Newmont Pajingo Internal Memo.

Natural Resources Canada (2007) Narrow Vein Mining Research Project (http://mmsd1.mms.nrcan.gc.ca/canmet/default.html).

Phillips, G. and Orr, L. (2007) Mineral Resource and Ore Reserve Report as of December 31, 2006. Pajingo Gold Mine Internal Report.

Villaescusa, E. (2002) Report on Acoustic Emission Testing of Jandam Core. West Australian School of Mines, Curtin University. 